OPEN ACCESS

Edited by:

Ondřej Šeda,

Charles University, Czechia

Reviewed by:

Lei Ye,

National Heart Centre Singapore,

Singapore

Luiza Ghila,

University of Bergen, Norway

*Correspondence:

Clayton E. Mathews

cxm@ufl.edu

Specialty section:

This article was submitted to

Diabetes: Molecular Mechanisms,

a section of the journal

Frontiers in Endocrinology

Received: 06 July 2021

Accepted: 05 October 2021

Published: 09 November 2021

Citation:

Armitage LH, Stimpson SE, Santostefano KE, Sui L, Ogundare S,

Newby BN, Castro-Gutierrez $R$, Huber MK, Taylor JP, Sharma P, Radichev IA, Perry DJ, Fredette NC, Savinov AY, Wallet MA, Terada N, Brusko TM, Russ HA, Chen J, Egli D and Mathews CE (2021) Use of Induced Pluripotent Stem Cells to

Build Isogenic Systems and Investigate Type 1 Diabetes.

Front. Endocrinol. 12:737276. doi: 10.3389/fendo.2021.737276

\section{Use of Induced Pluripotent Stem Cells to Build Isogenic Systems and Investigate Type 1 Diabetes}

\author{
Lucas H. Armitage ${ }^{1,2}$, Scott E. Stimpson ${ }^{1,2}$, Katherine E. Santostefano ${ }^{1,3,4}$, Lina Sui ${ }^{5}$, \\ Similoluwa Ogundare ${ }^{1,2}$, Brittney N. Newby ${ }^{1,2}$, Roberto Castro-Gutierrez ${ }^{6}$, \\ Mollie K. Huber ${ }^{1,2}$, Jared P. Taylor ${ }^{1}$, Prerana Sharma ${ }^{7}$, Ilian A. Radichev ${ }^{7}$, \\ Daniel J. Perry ${ }^{1,2}$, Natalie C. Fredette ${ }^{1,3}$, Alexei Y. Savinov ${ }^{7}$, Mark A. Wallet ${ }^{1,2,8}$, \\ Naohiro Terada ${ }^{1,3}$, Todd M. Brusko ${ }^{1,2}$, Holger A. Russ ${ }^{6}$, Jing Chen ${ }^{1,2}$, Dieter Egli ${ }^{5}$ \\ and Clayton E. Mathews ${ }^{1,2,3^{*}}$
}

\begin{abstract}
1 Department of Pathology, Immunology, and Laboratory Medicine, College of Medicine, University of Florida, Gainesville, FL, United States, ${ }^{2}$ University of Florida Diabetes Institute, University of Florida, Gainesville, FL, United States, ${ }^{3}$ Center for Cellular Reprogramming, College of Medicine, University of Florida, Gainesville, FL, United States, ${ }^{4}$ Century Therapeutics, iPSC Biology, Philadelphia, PA, United States, ${ }^{5}$ Department of Pediatrics, Naomi Berrie Diabetes Center, Columbia Stem Cell Initiative, Columbia University, New York, NY, United States, ${ }^{6}$ Barbara Davis Center for Diabetes, University of Colorado School of Medicine, Aurora, CO, United States, ${ }^{7}$ Children's Health Research Center, Sanford Research, Sioux Falls, SD, United States, ${ }^{8}$ Century Therapeutics, Immunology, Philadelphia, PA, United States
\end{abstract}

Type 1 diabetes (T1D) is a disease that arises due to complex immunogenetic mechanisms. Key cell-cell interactions involved in the pathogenesis of T1D are activation of autoreactive $T$ cells by dendritic cells $(D C)$, migration of $T$ cells across endothelial cells (EC) lining capillary walls into the islets of Langerhans, interaction of T cells with macrophages in the islets, and killing of $\beta$-cells by autoreactive CD8 ${ }^{+} \mathrm{T}$ cells. Overall, pathogenic cell-cell interactions are likely regulated by the individual's collection of genetic T1D-risk variants. To accurately model the role of genetics, it is essential to build systems to interrogate single candidate genes in isolation during the interactions of cells that are essential for disease development. However, obtaining single-donor matched cells relevant to T1D is a challenge. Sourcing these genetic variants from human induced pluripotent stem cells (iPSC) avoids this limitation. Herein, we have differentiated iPSC from one donor into DC, macrophages, EC, and $\beta$-cells. Additionally, we also engineered $T$ cell avatars from the same donor to provide an in vitro platform to study genetic influences on these critical cellular interactions. This proof of concept demonstrates the ability to derive an isogenic system from a single donor to study these relevant cell-cell interactions. Our system constitutes an interdisciplinary approach with a controlled environment that provides a proof-of-concept for future studies to determine the role of disease alleles (e.g. IFIH1, PTPN22, SH2B3, TYK2) in regulating cell-cell interactions and cell-specific contributions to the pathogenesis of T1D.

Keywords: type 1 diabetes mellitus, isogenic, human, beta cells, immunity, autoimmunity, induced pluripotent stem cells 


\section{INTRODUCTION}

Type 1 diabetes (T1D) is a debilitating autoimmune disease that is caused by $\mathrm{T}$ cell-mediated destruction of $\beta$-cells in the islets of Langerhans in the pancreas. This results in lifelong dependence on exogenous insulin and can lead to many complications that degrade quality of life for patients living with T1D. With the advent of genome-wide association studies (GWAS) a big picture view of the genetic contributions of T1D has come into focus. While human leukocyte antigen (HLA) loci, encoding the major histocompatibility (MHC) proteins, make up the bulk of genetic risk for T1D, over 100 non-HLA loci have been identified with polymorphisms that increase or decrease risk for T1D (1-12). However, studying the phenotypic outcome of these polymorphisms has proven difficult due to the heterogeneous nature of the human population and the inaccessibility of pancreatic tissue from individuals with signs of islet autoimmunity (i.e. islet autoantibodies) and individuals with clinical T1D.

Over the past half-century, immune and non-immune cells have been implicated in T1D (13-15). Key interactions involved in the pathogenesis of T1D in humans (Figure 1) include; A) the initial interactions between dendritic cells (DC) and $\beta$-cells where DC uptake $\beta$-cell antigens from dead, dying, or stressed $\beta$-cells, B) the activation of autoreactive $\mathrm{CD}^{+}$and $\mathrm{CD}^{+} \mathrm{T}$ cells by the $\beta$-cell antigen-loaded DC, C) the interaction between autoreactive $\mathrm{CD} 8^{+} \mathrm{T}$ cells and the endothelial cells (EC) lining the capillaries that supply the islets of Langerhans as autoreactive $\mathrm{CD}^{+} \mathrm{T}$ cells undergo transendothelial migration to access the islets, D) the targeting of $\beta$-cells for cell-mediated lysis by autoreactive $\mathrm{CD}^{+} \mathrm{T}$ cells, and $\mathrm{E}$ ) the in situ amplification of $\mathrm{T}$ cell responses by $\mathrm{DC}$ and macrophages in the islets. Genetics influence T1D pathogenesis and deleterious cellular function; however, genes implicated in T1D do not function in isolation. Numerous implicated genes cluster into pathways likely to create situations where different combinations of candidate genes can contribute equally to increased T1D risk (16). The development of a simple and flexible human model is essential to deconvolute genetic risk and make progress in understanding human T1D. We propose the use of models constructed from single-donor iPSCderived cells. The utility of iPSC to investigate the relationship between rare and common gene variants and gene expression in pluripotent cells was recently highlighted (17).

Human iPSC exhibit similar gene expression patterns to human embryonic stem cells (ESC) and have the capacity to differentiate to all cell types of the human body. Generating iPSC and differentiating them to the cell types of interest (Figure 1) from a single donor preserves the genetic background and integrity of disease alleles, potentially making for an excellent isogenic model system to study T1D pathogenesis. In support of these isogenic systems, advances in stem cell technologies have

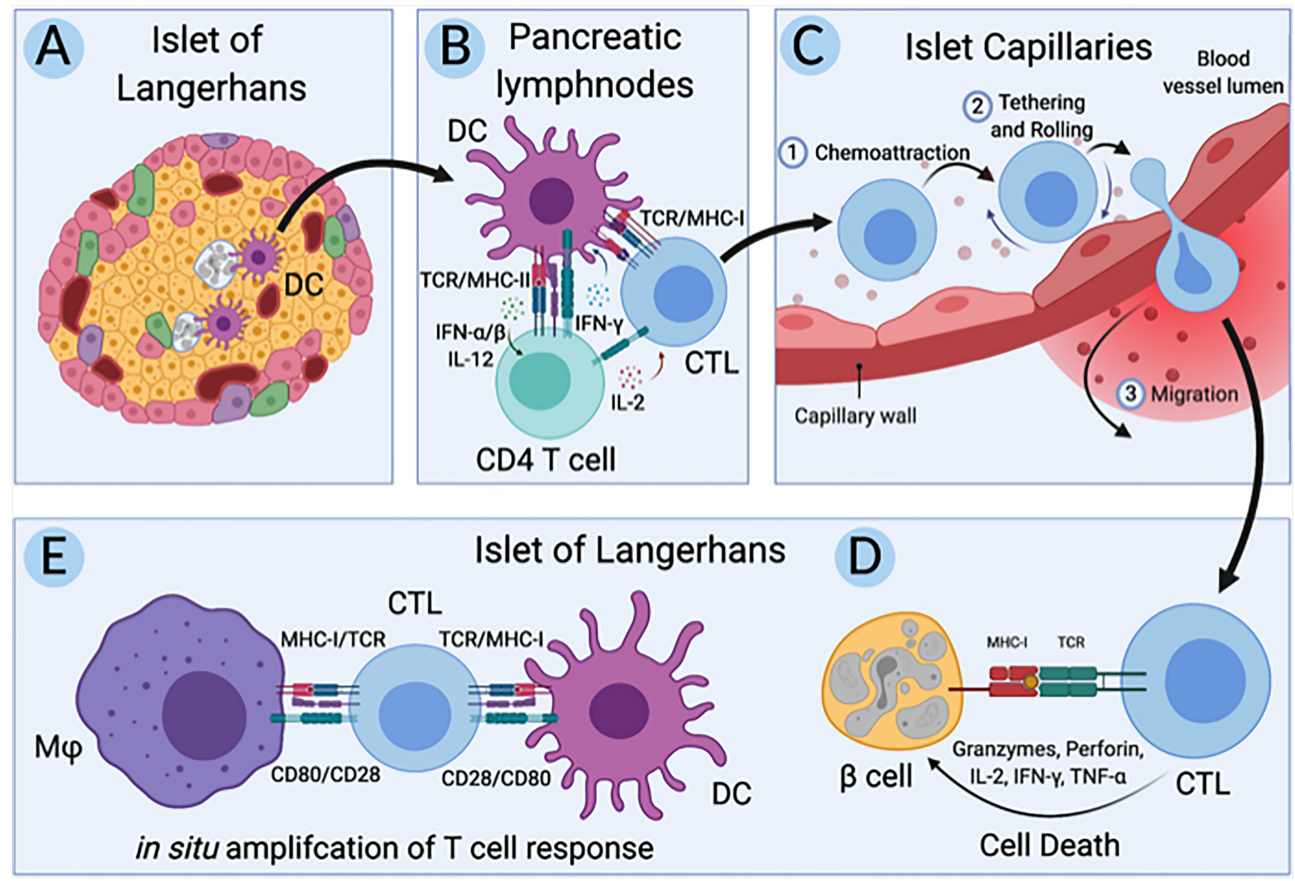

FIGURE 1 | Key cellular interactions involved in pathogenesis of T1D in humans. (A) First dendritic cells (DC) uptake antigen from dead, dying, and stressed $\beta$-cells in the islets of Langerhans in individuals at risk for type 1 diabetes (T1D). (B) Second, these $\beta$-cell-antigen-loaded DC migrate to the pancreatic lymph nodes where they present $\beta$-cell antigen to autoreactive $\mathrm{CD}^{+}$and $\mathrm{CD}^{+} \mathrm{T}$ cells, initiating an adaptive immune response. (C) Third, these autoreactive CD8 ${ }^{+} \mathrm{T}$ cells, also called cytotoxic T lymphocytes (CTLs), migrate back to the pancreas and undergo transendothelial migration across the endothelium lining capillaries that supply the islets of Langerhans. (D) Fourth, these CTLs directly target and lyse $\beta$-cells while (E) resident and infiltrating macrophages and DC amplify the CTL response in situ. Created with BioRender.com. 
resulted in protocols allowing for differentiation of iPSC to functional replicas of cells essential for T1D, including the hard to access $\beta$-cells. Additionally, methods for engineering primary human $\mathrm{T}$ cells have advanced our understanding of immunity and autoimmunity (18-20). Here we selected three candidate iPSC lines to build the isogenic system, 1-018, 1-023, and 2395 , that had previously been differentiated to stem cell derived beta-like cells ( $\mathrm{sBC}$ ), as this is the most time intensive and thus the rate limiting step for construction of these isogenic models (21-23). Based on HLA requirements and necessity of successful differentiation into pancreatic $\beta$-cells, endothelial cells, macrophages, and dendritic cells, line 2395 was selected. In addition, $\mathrm{T}$ cells were purified from this same donor. Employing the most recent and advanced methods for culturing and differentiating iPSC that have similar functionality to cells in vivo, we show that these iPSC-derived cells can be used for modeling and interrogating cell-cell interactions that are relevant to the pathogenesis of T1D (Figure 1). Utilizing these cellular approaches will allow investigators to examine relationships of genotype with cell function and cellcell interactions.

\section{MATERIALS AND METHODS}

\section{Reprogramming Somatic Cells to iPSC}

The generation and characterization of the iPSC lines 1-018 and 1-023 was previously described (21-23). Derivation of iPSC from donor 2395 was as previously described (24). Briefly, peripheral blood was collected from donor 2395 under informed consent by the University of Florida Diabetes Institute Study Bank with Institutional Review Board approval (IRB201400703). CD34 ${ }^{+}$ peripheral stem cells were isolated from peripheral blood and expanded using the Complete Kit for Human Whole Blood CD $34^{+}$Cells (Stem Cell Technologies, Vancouver, Canada) following the manufacturer's protocol. Expanded CD $34^{+}$ peripheral stem cells were transduced with the Sendai viral vector, SeVdp(KOSM)302L, which encodes the four reprogramming factors, OCT4, SOX2, KLF4, and c-MYC $(20,25,26)$. Following transduction, cells were cultured on hESC qualified Matrigel- (Corning, Corning, NY) coated dishes in ReproTeSR medium (Stem Cell Technologies) and medium was changed daily until iPSC colonies were observed. iPSC colonies were manually isolated then expanded on Matrigelcoated dishes in mTeSR1 medium (StemCell Technologies, Vancouver, Canada).

Following reprogramming, donor 2395 iPSC were assessed for pluripotency using the StemDiff Trilineage Differentiation Kit (StemCell Technologies) following the manufacturer's protocol. iPSC were subjected to karyotyping to verify a normal karyotype by Cell Line Genetics (Madison, WI, USA). Undifferentiated donor 2395 iPSC were stained with anti-NANOG-AF647, anti-SSEA-4-PE, and anti-Oct-4-AF488 (BioLegend, San Diego, CA) using the Fixation/Permeabilization Solution kit from BD Biosciences (San Jose, CA) and analyzed on an Accuri C6 flow cytometer (BD Biosciences). Information for all antibodies used during the included studies are contained in Supplementary Table 1.

\section{Differentiation of iPSC to Stem Cell-Derived Beta-Like Cells}

The iPSC lines used in this study, 1-018, 1-023, and 2395, were initially selected because they had previously been differentiated to stem cell derived beta-like cells (sBC). The iPSC lines, 1-018 and 1-023, were differentiated to $\mathrm{sBC}$ as previously described (22). Donor 2395 iPSC were maintained on Matrigel-coated 6 well plates in mTeSR + medium (StemCell Technologies) and differentiated to sBC as previously described $(27,28)$. Differentiation to sBC was carried out in suspension-based, low attachment suspension culture plates as described (29) or in an ABLE bioreactor magnetic stirring system (Reprocell, Beltsville, MD, USA) as follows. For differentiations, $70-80 \%$ confluent iPSC cultures were washed with PBS and incubated in TrypLE Express Enzyme (Gibco, Watham, MD, USA) for $8 \mathrm{~min}$ at $37^{\circ} \mathrm{C}$ followed by quenching with $\mathrm{mTeSR}+$. Bioreactors were seeded at $0.5 \times 10^{6}$ cells $/ \mathrm{mL}$ in $\mathrm{mTeSR}+$ medium supplemented with $10 \mu \mathrm{M}$ ROCK inhibitor. Bioreactors were placed on a magnetic stirring system set at 60 RPM in a cell culture incubator at $5 \% \mathrm{CO}_{2}$ to induce sphere formation for $48-72$ hours. To begin the differentiation process, spheres were collected in a $50 \mathrm{~mL}$ Falcon tube, allowed to settle by gravity, washed once with RPMI (Gibco) + 0.2\% FBS, and re-suspended in day 0 medium (RPMI containing $0.2 \%$ FBS, 1:5,000 ITS (Gibco), $100 \mathrm{ng} / \mathrm{mL}$ Activin-A (R\&D Systems), and $3 \mu \mathrm{M}$ CHIR (StemCell Technologies)). The differentiation medium was changed daily by letting spheres settle by gravity for 3-10 min. Approximately $80 \%$ of spent supernatant was removed by aspiration, fresh medium was added, and bioreactors were placed back on stirrer system. Differentiation media are as follows: day 1-2, RPMI containing 0.2\% FBS, 1:2,000 ITS, and $100 \mathrm{ng} / \mathrm{mL}$ Activin A; day 3-4, RPMI containing 2\% FBS, 1:1,000 ITS, and 50 ng/mL KGF (Peprotech); day 5, DMEM with $4.5 \mathrm{~g} / \mathrm{L}$ D-glucose (Gibco) containing 1:100 SM1 (StemCell Technologies), 1:100 NEAA (Gibco), $1 \mathrm{mM}$ Sodium Pyruvate (Gibco), 1:100 GlutaMAX (Gibco), 3 nM TTNPB, (R\&D Systems), $250 \mathrm{nM}$ Sant-1 (R\&D Systems), $250 \mathrm{nM}$ LDN (StemCell Technologies), $30 \mathrm{nM}$ PMA (Sigma Aldrich), $50 \mu \mathrm{g} / \mathrm{mL}$ 2-phospho-L-ascorbic acid trisodium salt (VitC; Sigma); day 6, DMEM with $4.5 \mathrm{~g} / \mathrm{L} \mathrm{D}$ glucose containing 1:100 SM1, 1:100 NEAA, 1 mM Sodium Pyruvate, 1:100 GlutaMAX, $3 \mathrm{nM}$ TTNPB and $50 \mu \mathrm{g} / \mathrm{mL}$ VitC; day 7, DMEM containing 1:100 SM1, 1:100 NEAA, $1 \mathrm{mM}$ Sodium Pyruvate, 1:100 GlutaMAX, $3 \mathrm{nM}$ TTNPB and $50 \mu \mathrm{g} /$ mL VitC; day 8-9, DMEM containing 1:100 SM1, 1:100 NEAA, 1 mM Sodium Pyruvate, 1:100 GlutaMAX, 200 ng/ml EGF and 50 ng/mL KGF; days 10-16, DMEM containing 2\% fraction V BSA, 1:100 NEAA, $1 \mathrm{mM}$ Sodium Pyruvate, 1:100 GlutaMAX, 1:100 ITS, $10 \mu \mathrm{g} / \mathrm{ml}$ Heparin (Sigma), $2 \mathrm{mM} \mathrm{N}$-Acetyl-L-cysteine (Cysteine; Sigma), $10 \mu \mathrm{M}$ Zinc sulfate heptahydrate (Zinc; Sigma), 1x BME, $10 \mu \mathrm{M}$ Alk5i II RepSox (R\&D Systems), 2 $\mu \mathrm{M}$ 3,3',5-Triiodo-L-thyronine sodium salt (T3; Sigma), $0.5 \mu \mathrm{M}$ LDN, $1 \mu \mathrm{M}$ Gamma Secretase Inhibitor XX (XXi) (AsisChem, Waltham, MA, USA) and 1:250 $1 \mathrm{M} \mathrm{NaOH}$ to adjust $\mathrm{pH}$ to 7.4 ; 
day 17+, CMRL (Gibco) containing 1\% BSA, 1:100 NEAA, 1 mM Sodium Pyruvate, 1:100 GlutaMAX, $10 \mu \mathrm{g} / \mathrm{mL}$ Heparin, $2 \mathrm{mM}$ Cysteine, $10 \mu \mathrm{M}$ Zinc, 1x BME, $10 \mu \mathrm{M}$ Alk5i II RepSox, $1 \mu \mathrm{M}$ T3, $50 \mu \mathrm{g} / \mathrm{mL} \mathrm{VitC}$, and 1:250 NaOH to adjust $\mathrm{pH}$ to $\sim 7.4$ (also referred to as maturation medium). All media contained $1 \mathrm{x}$ PenStrep (Gibco). Medium was changed every other day starting day 11. Validation and function of $\mathrm{sBC}$, including staining for glucagon and insulin as well as glucose-stimulated insulin secretion were performed as previously described $(22,28,29)$.

\section{HLA Typing of iPSC}

DNA was isolated from iPSC lines, 1-018, 1-023, and 2395, and subjected to genotyping at 974,650 unique loci using a custom SNP array. The Axiom Precision Medicine Research Array (ThermoFisher Scientific) was modified to include content from the ImmunoChip v2.0 (30) as well as previously reported credible T1D risk variants (10), and additional content to create the UFDIchip. UFDIchips were processed on an Affymetrix Gene Titan instrument with external sample handling on a BioMek FX dual arm robotic workstation. Data processing and quality control pipelines included standard quality control procedures at the SNP, sample, and plate levels using Axiom ${ }^{\mathrm{TM}}$ Analysis Suite 3.0 (ThermoFisher Scientific) set to the default stringency thresholds as recommended, as well as for genetic versus reported sex. The analysis pipeline also includes race imputation using EthSeq (31), relatedness using KING (32), and imputation to $40 \mathrm{M}$ SNPs using the Human Reference Consortium (version 1.1) with the Michigan Imputation Server (33). The array also includes dense coverage of the highly polymorphic HLA region allowing accurate imputation of HLA haplotypes to 4-digit resolution (34). SNP data are available upon request. HLA alleles arranged into putative extended haplotypes using the Allele Frequency Net Database (http://allelefrequencies.net/).

\section{Differentiation of iPSC to Monocytes, Monocyte-Derived Macrophages, and Monocyte-Derived Dendritic Cells}

Donor 2395 iPSC were differentiated to monocytes, monocytederived dendritic cells (moDC), and monocyte-derived macrophages (MDM), as described (35). Briefly, iPSC were differentiated to hematopoietic progenitors using the STEMdiff Hematopoietic Kit (StemCell Technologies) over 12 days. On day 12 , hematopoietic progenitors were harvested and the hemogenic endothelium left behind in the 12 -well plate was cultured in X-VIVO15 (Lonza, Basel, Switzerland) supplemented with $\beta$-mercaptoethanol (Gibco), Glutamax (Gibco), 25 ng/mL recombinant human IL-3 (rhIL-3, PeproTech, Rocky Hill, NJ), and $100 \mathrm{ng} / \mathrm{mL}$ recombinant human M-CSF (rhM-CSF, PeproTech). The hemogenic endothelium transitioned into monocyte factories and produced non-adherent $\mathrm{CD} 14^{+}$ monocytes that can be harvested repeatedly starting around day 21. Thereafter, CD14 ${ }^{+}$cells are harvested every 2-7 days. Monocyte factories were replaced on Day 94. iPSC-monocytes were differentiated to iPSC-MDM as previously described (24, 35). Briefly, iPSC-monocytes were plated in high-glucose DMEM supplemented with 10\% FBS (Genesee Scientific, San Diego, CA) or $10 \%$ human serum (Atlanta Biologicals, Flowery Branch, GA), $1000 \mathrm{U} / \mathrm{mL}$ Penicillin/streptomycin (Genessee Scientific), Glutamax, and $10 \mathrm{ng} / \mathrm{ml}$ of rhM-CSF for 7 days before use in experiments. iPSC-monocytes from Donor 2395 were differentiated to iPSC-moDC as previously described (36). Briefly, the CD14 ${ }^{+}$iPSC-monocytes were plated in GMP DC medium (CellGenix, Freiburg im Breisgau, Germany) supplemented with Glutamax, $50 \mathrm{ng} / \mathrm{mL}$ recombinant human IL-4 (PeproTech), and $50 \mathrm{ng} / \mathrm{mL}$ recombinant human GM-CSF (PeproTech) and cultured for 6 days. On day 7, iPSC-moDC were plated for experiments.

\section{Differentiation of iPSC to Endothelial Cells}

Donor 2395 iPSC were differentiated to iPSC-derived endothelial cells (iPSC-EC) as previously described (37). This newly published protocol was adapted from a previously published protocol (38). Briefly, donor 2395 iPSC colonies were dissociated to single cells with Accutase (StemCell Technologies) and plated on Matrigel-coated plates at a density of $5 \times 10^{5}$ cells per $\mathrm{cm}^{2}$ in mTESR1 medium (StemCell Technologies) supplemented with $10 \mathrm{ng} / \mathrm{mL}$ of the RHO/ROCK pathway inhibitor, Y-27632 (StemCell Technologies) on day 0 . On day 1 , the medium was changed to STEMdiff Mesoderm Induction medium (StemCell Technologies) and the medium was changed daily. On day 3, medium was replaced with STEMdiff APEL medium (StemCell Technologies) supplemented with $25 \mathrm{ng} / \mathrm{mL}$ BMP-4 (PeproTech) and $50 \mathrm{ng} / \mathrm{mL}$ VEGF (Peprotech). On day 5, the medium was replaced with fresh STEMdiff APEL medium supplemented with $25 \mathrm{ng} / \mathrm{mL}$ BMP-4 and $50 \mathrm{ng} / \mathrm{mL}$ VEGF. On day $7, \mathrm{CD}_{3} 4^{+}$cells were enriched with the EasySep Human Cord Blood CD34 Positive Selection Kit II (StemCell Technologies) without using the RosetteSep ${ }^{\text {TM }}$ Human Cord Blood CD34 Pre-Enrichment Cocktail. The enriched iPSCderived $\mathrm{CD}_{3} 4^{+}$cells were plated at a density of $3.5 \times 10^{5}$ cells per $\mathrm{cm}^{2}$ onto fibronectin (Millipore) coated dishes $\left(5 \mathrm{ng} / \mathrm{cm}^{2}\right)$ and cultured in Endothelial Growth Medium 2 (EGM2, Lonza) supplemented with $50 \mathrm{ng} / \mathrm{mL}$ VEGF with medium changes every other day until they reached confluency. After the 1st passage, cells were cultured in regular EGM2 without extra VEGF and split at a 1:3 ratio onto fibronectin-coated plates $\left(5 \mathrm{ng} / \mathrm{cm}^{2}\right)$ as they approached confluency. iPSC-EC were cryopreserved in $0.5 \mathrm{~mL}$ of CryoStor CS10 Freeze Media (BioLife Solutions, Bothell, WA) at $1 \times 10^{6}$ cells/vial according to the manufacturer's protocol. Phase contrast photomicrographs of 2395 iPSC-EC were collected using an EVOS FL Cell Imaging System (Fisher Scientific).

\section{Generation of CD8 ${ }^{+}$T Cell Avatars From Donor 2395}

Antigen-specific $\mathrm{CD}^{+} \mathrm{T}$ Cell avatars were produced and validated as previously published (20). Briefly, $\mathrm{CD}^{+} \mathrm{T}$ cells were isolated from peripheral blood of donor 2395 via negative selection using the RosetteSep Human $\mathrm{CD}^{+} \mathrm{T}$ Cell Enrichment Cocktail (StemCell Technologies) according to the manufacturer's protocol. Naïve $\mathrm{CD}^{+} \mathrm{T}$ cells $\left(\mathrm{CD}^{-} 5 \mathrm{RA}^{+} \mathrm{CD} 45 \mathrm{RO}^{-}\right)$were isolated by FACS with a 
FACSAria III Cell Sorter (BD Biosciences). Naïve CD8 ${ }^{+} \mathrm{T}$ cells were activated for two days with Human T-Activator CD3/CD28 Dynabeads (ThermoFisher Scientific, Waltham, MA). After two days, cells were transduced with lentiviral vectors, either pCCL.IGRPopt.eGFP, encoding a TCR recognizing an HLA$A^{\star} 02-01$-restricted epitope derived from the T1D-relevant autoantigen, glucose-6-phosphatase 2 (G6PC2) commonly referred to as islet-specific G6CP-related protein (IGRP) $(39,40)$ or LV.Mart1.TCR.RK, encoding a TCR recognizing an HLA-A ${ }^{\star} 02$ 01-restricted epitope derived from the non-T1D-relevant autoantigen, MART-1 $(18,19)$. Following transduction, the IGRP and the MART-1 CD8+ T cell avatars (IGRP avatars and MART-1 avatars) were expanded for 7 more days then cryopreserved.

\section{Co-Culturing Donor 2395 iPSC-moDC and iPSC-MDM With Donor 2395 CD8 ${ }^{+}$T Cells}

To verify the ability of iPSC-moDC and iPSC-MDM to induce antigen-specific $\mathrm{T}$ cell expansion, iPSC-moDC and MDM were treated with $10 \mathrm{ng} / \mathrm{mL}$ of LPS (Sigma-Aldrich, St. Louis, MO) and $10 \mathrm{ng} / \mathrm{mL}$ of IFN $\gamma$ (Peprotech) for 48 hours. After iPSCmoDC and MDM were activated for 48 hours, they were loaded for 2 hours with both CEFX Ultra SuperStim Pool MHC-I and MHC-II Subsets (JPT innovative peptide solutions, Berlin, Germany), for a total of 80 MHC Class I restricted epitopes and $68 \mathrm{MHC}$ Class II restricted epitopes derived from a broad range of common human viruses, as well as Clostridium tetani and Toxoplasma gondii. After 2 hours, iPSC-moDC and MDM were washed with $\mathrm{T}$ cell expansion medium (RPMI supplemented with 10\% HyClone FBS (GE Healthcare, Chicago, IL, USA), $1000 \mathrm{U} / \mathrm{mL}$ Penicillin/streptomycin, $1 \mathrm{mM}$ Sodium Pyruvate (Corning), 10mM HEPES (Corning), nonessential amino acids (Corning), Glutamax, and $\beta$ mercaptoethanol) and the medium was replaced with $\mathrm{T}$ cell expansion medium. Freshly isolated total $\mathrm{T}$ cells from donor 2395 were stained with CellTrace CFSE (ThermoFisher), added to the CEFX peptide-loaded iPSC-moDC or MDM and cocultured for 5 days. After 5 days, expansion of total T cells was analyzed via flow cytometry on an Accuri C6 Flow Cytometer.

\section{In Vitro Hydrodynamic Flow Chamber Adhesion Assay}

The in vitro hydrodynamic flow chamber adhesion assay was performed as previously described $(15,41)$. Briefly, iPSC-EC were grown in monolayers to $95-100 \%$ confluence on a $0.2 \mathrm{~mm}$ Luer $\mu$ slide (channel slide) pre-coated with fibronectin. The iPSC-EC monolayers were then loaded with either vehicle solution, IGRP $_{265-273}$ (the antigenic peptide recognized by the IGRP avatars), or Melan- $\mathrm{A}_{26-35}$ (the antigenic peptide recognized by the MART-1 avatars) at a final concentration of $10 \mu \mathrm{g} / \mathrm{ml}$ and incubated overnight. The next day, the iPSC-EC-containing channel slide(s) were loaded on the stage of a confocal microscope heated to $37^{\circ} \mathrm{C}$. Ten thousand MART-1 or IGRP avatars labeled with $200 \mathrm{nM}$ CellTracker Green (Molecular Probes, Eugene, OR) were added to the channel slide and allowed to settle for 30 minutes. HBSS buffer with $\mathrm{MgCl}_{2}$ and $\mathrm{CaCl}_{2}$ was then flowed across the channel slide by a syringe-driven pump at a series of increasing flow rates ranging from 1 to 80 dyne $/ \mathrm{cm}^{2}$. After passing the buffer through the channel slide for 1 minute for each shear flow rate, bright field and fluorescent images of the slide were acquired by confocal microscopy. $\mathrm{T}$ cells that remained attached after each flow rate were then counted using ImageJ software (42).

\section{Chromium Release Assay}

The chromium release assay to assess antigen-specific targeting of sBC or the immortalized human $\beta$-cell line, BetaLox 5 cells ( $\beta$ L5), by donor 2395 avatars was performed as previously described $(20,43)$. Briefly, sBC clusters from donor 2395, 1-018, or 1-023 were dispersed in enzyme-free Cell Dissociation Buffer (Gibco) for 10 minutes at $37^{\circ} \mathrm{C}$ with gentle pipetting. Dispersed sBC were plated at 40,000 cells/well or $\beta$ L5 cells were plated at 10,000 cells/well in 96well flat-bottom plates. Target cells were loaded with Melan- $\mathrm{A}_{27-35}$. Target cells were then labeled with ${ }^{51} \mathrm{Cr}$ at $1 \mu \mathrm{Ci} /$ well for 3 hours and then washed 3 times with culture medium. Donor 2395 MART-1 avatars were added at effector to target (E:T) ratios of $0: 1,5: 1$, and 10:1 and co-cultured for 16 hours. Afterwards, the supernatants were collected, cells were lysed in $2 \%$ SDS, and cell lysate was collected. ${ }^{51} \mathrm{Cr}$ release was measured with a gamma counter and specific lysis was calculated as follows:

$$
\begin{aligned}
\% \text { Specific Lysis }= & \text { Experimental } \frac{(\# \text { Release })}{(\# \text { Release })+(\# \text { Lysate })} \\
& - \text { Spontaneous } \frac{(\# \text { Release })}{(\# \text { Release })+(\# \text { Lysate })}
\end{aligned}
$$

where spontaneous release is the 0:1 E:T ratio and experimental release is measured in the 5:1 and 10:1 E:T ratios.

\section{Statistical Analysis}

All statistical analyses were performed in GraphPad Prism version 8.4.3 (San Diego, CA) using unpaired Student's t test, one-way ANOVA, or two-way ANOVA, as indicated in the figure legends.

\section{RESULTS}

\section{Reprogramming Donor 2395 CD34 ${ }^{+}$ Peripheral Stem Cells to iPSC}

Our proposed isogenic system for T1D (Figure 1) requires constant supplies of $\beta$-cells, DCs, T cells, endothelial cells, and macrophages from the same donor. The major goal of this effort was to determine if iPSC lines had potential to differentiate into all of these cell types allowing construction of a fully isogenic system. For the work described here all of these cell types, except for T cells, were to be differentiated from donor iPSC lines. Before working with these iPSC lines, they were all verified to express pluripotency markers and have a normal karyotype. iPSC from lines 1-023 and 1-018 were validated and published previously (21-23). iPSC generated from donor 2395 showed similar morphology to normal hESCs (Figure 2A) and expressed the pluripotency markers, Oct4, SSEA-4, and NANOG (Figure 2B). 2395 iPSC were pluripotent, they differentiated into $\mathrm{Nestin}^{+}$ectoderm, FoxA2 ${ }^{+}$Sox $17^{+}$ endoderm, and $\mathrm{NCAM}^{+}$Brachyury $^{+}$mesoderm (Figure 2C). 

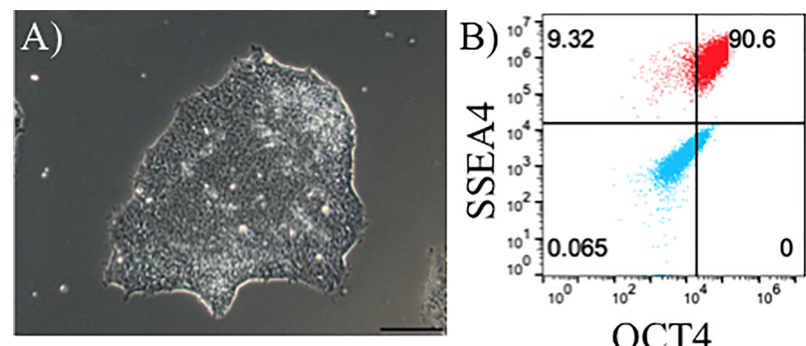

OCT4

C) Ectoderm

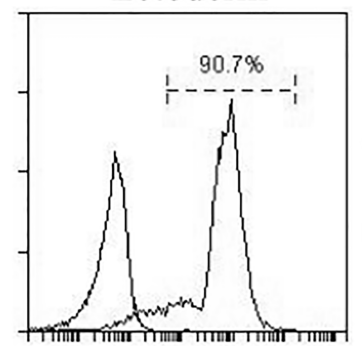

Nestin

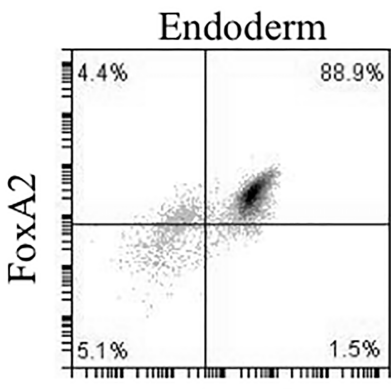

Sox 17

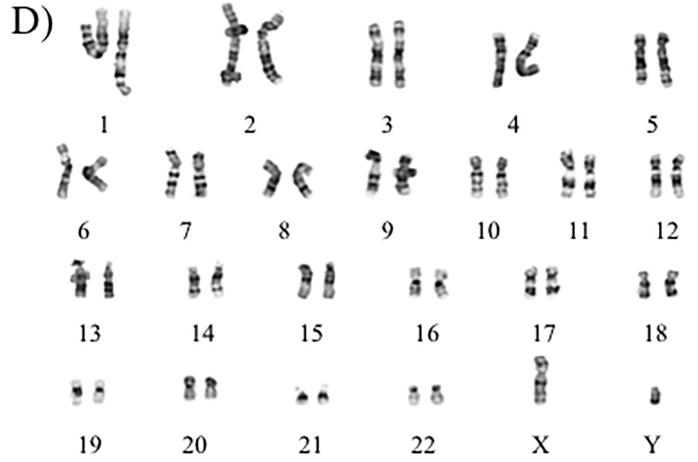

Isotype

Stained

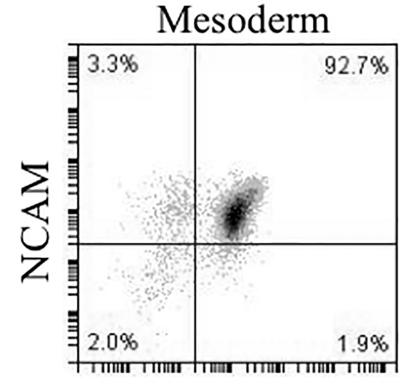

Brachyury

FIGURE 2 | Verification of pluripotency of donor 2395 iPSC. (A) A phase contrast image of an iPSC colony from donor 2395 showing densely packed cells with a defined border characteristic of iPSC. (B) Donor 2395 iPSC are positive for Oct4, SSEA4, and NANOG expression. (C) Donor 2395 iPSC express Nestin when differentiated to ectoderm, express FoxA2 and Sox17 when differentiated to endoderm, and express NCAM and Brachyury when differentiated to mesoderm.

(D) Karyotypic analysis of donor 2395 iPSC reveals a normal karyotype.

Karyotyping analysis of 2395 iPSC showed a normal chromosome count of 46,XY (Figure 2D).

\section{Donor 2395 iPSC Differentiate Into Insulin Producing Beta-Like Cells That Respond to Glucose}

$\beta$-cells participate in the pathogenesis of T1D by shedding antigen (Figure 1A) to initiate the autoimmune response and are also targeted for destruction by the immune system in T1D (Figure 1D). Any fully isogenic system to study these steps in T1D (Figure 1) will require a renewable source of islets or $\beta$ cells. Stem cell-derived $\beta$-cells (sBC) can fulfill this need. With published protocols for differentiation of $\beta$-cells available, we proceeded to differentiate iPSC from the three lines $(1-018,1-$ 023 , and 2395) into sBC. Lines 1-018 and 1-023 have previously been differentiated into validated $\mathrm{sBC}$ in islet like clusters with expression of c-peptide and secretion of insulin $(22,44)$. iPSC from line 2395 were differentiated to sBC by first differentiating to definitive endoderm (DE). Cultures were only moved forward if they reached $>80 \% \mathrm{SOX}^{+} 7^{+}$at the DE stage (Figure 3A). At the $\beta$-like stage, cells reached $28.1 \pm 3.0 \%$ insulin $^{+}$glucagon (Figures 3B, C; $n=3$ separate differentiations). Fluorescent micrographs (Figure 3D) demonstrate an islet-like cluster of sBC from 2395 with cells expressing NXK6.1, PDX-1, and c-peptide. To verify that the $\mathrm{sBC}$ were functional, those differentiated from $1-018,1-023$, and 2395 were subjected to static glucosestimulated insulin secretory assays and compared to primary human islets. Basal insulin release at $3 \mathrm{mM}$ glucose in human islets $[2.3 \pm 1.8 \mu \mathrm{g}$ insulin/10 ng DNA $(\mathrm{n}=6)]$ was higher than that observed from all three sBC clusters $[1-023(0.051 \pm 0.043 \mu \mathrm{g}$ insulin/10 ng DNA $(\mathrm{n}=3)], 2395[0.04 \pm 0.01 \mu \mathrm{g}$ insulin/10 ng DNA $(n=6)]$, and 1-018 [0.007 $\pm 0.005 \mu \mathrm{g}$ insulin/10 ng DNA $(n=3)]$. Clusters from all three lines secreted insulin, albeit less than the average stimulation index of primary islets (Figure 3E). 
A

A Definitive endoderm

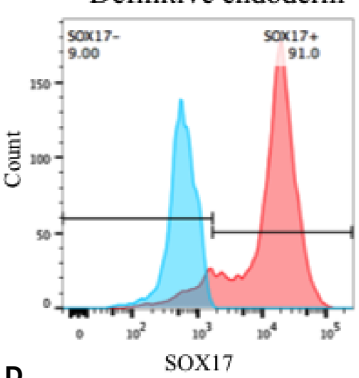

D
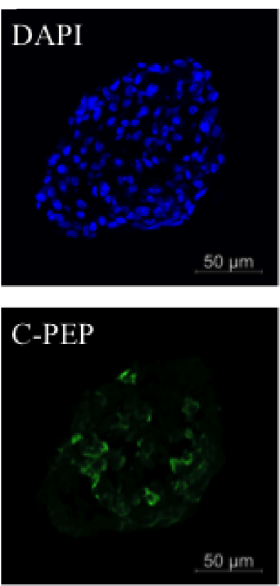

E

Stimulation Index-No Cytomix

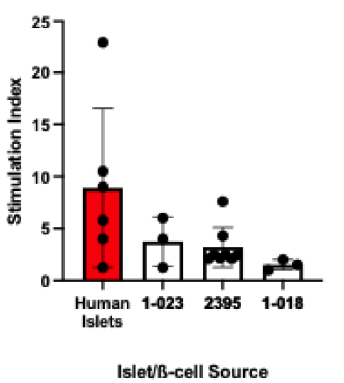

B

Beta cell stage

Undifferentiated Control

Differentiated 2395 iPSC
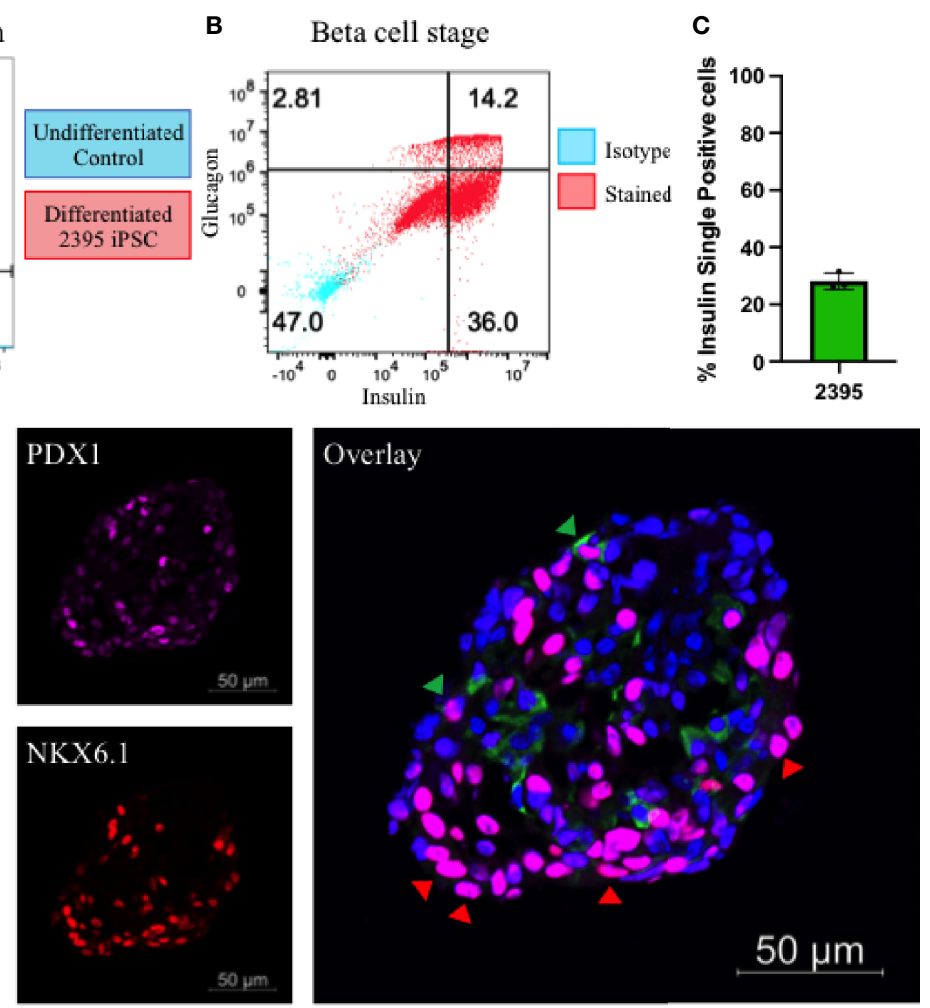

NKX6.1

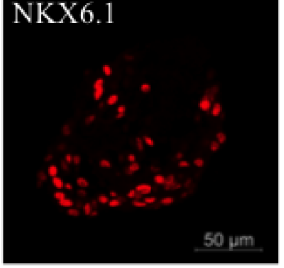


TABLE 1 | iPSC Donor Demographics and HLA Alleles for lines 1-018, 1-023, and 2395.

\begin{tabular}{|c|c|c|c|c|c|c|c|c|c|}
\hline Donor & Age at Study & Sex & T1D Status & Age at Onset & HLA-A & HLA-B & HLA-DQA1 & HLA-DQB1 & HLA-DRB1 \\
\hline \multirow[t]{2}{*}{$1-018$} & 32 & Female & T1D & 10 & 0101 & 1801 & 0301 & 0302 & 0402 \\
\hline & & & & & 3101 & 7301 & 0301 & 0201 & 0405 \\
\hline \multirow[t]{2}{*}{$1-023$} & 23 & Male & Control & Not applicable & 0201 & 3501 & 0102 & 0502 & 1101 \\
\hline & & & & & 6801 & 5101 & 0501 & 0301 & 1506 \\
\hline \multirow[t]{2}{*}{2395} & 52 & Male & Control & Not applicable & 2901 & 4403 & 0201 & 0202 & 0701 \\
\hline & & & & & 0201 & 4002 & 0505 & 0301 & 0701 \\
\hline
\end{tabular}

Alleles are arranged into putative extended haplotypes using the Allele Frequency Net Database (http://allelefrequencies.net/).

\section{Donor 2395 iPSC Efficiently Differentiate to Monocytes, MDM, and MoDC}

While the initiating events in T1D are not decisively characterized, initiating a productive $\mathrm{T}$ cell response requires at least two signals during the interaction of APC with T cells (Figure 1B). The first signal is binding of the TCR on the T cell to its cognate antigen/MHC complex on an APC and the second signal is the costimulatory signal in the form of co-receptors on the $\mathrm{T}$ cell binding their respective ligands on an APC (e.g. CD28 binding CD80/CD86, CD27 binding CD70, CD226 binding CD155, OX-40 binding OX-40L, etc.) $(45,46)$. APC such as $\mathrm{DC}$ and macrophages serve to initiate $\mathrm{T}$ cell responses in the lymph nodes and enhance $\mathrm{T}$ cell responses at sites of inflammation. In order to model interactions between macrophages and $\mathrm{T}$ cells or $\mathrm{DC}$ and $\mathrm{T}$ cells, we differentiated donor 2395 iPSC to monocytes, then MDM and moDC (Figure 4). Similar to primary classical peripheral blood monocytes, these iPSC-monocytes are $\mathrm{CD} 14^{+} \mathrm{CD} 64^{+} \mathrm{CD} 16^{-}$ (Figure 4A). Also similar to their primary counterparts, iPSC-

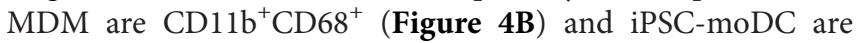
MHC-II ${ }^{+} \mathrm{CDllc}^{+}$(Figure 4C). Attempts were made to differentiate the iPSC line, 1-023, to monocytes however they never produced $\mathrm{CD} 34^{+}$hematopoietic progenitors following hematopoietic differentiation and they also never produced CD $14^{+}$monocytes following monocyte induction. Due to the inability of 1-023 iPSC to differentiate into Monocytes, MDM, and MoDC, we prioritized iPSC line 2395 for the remaining studies.

\section{Donor 2395 iPSC-moDC and iPSC-MDM Elicit Donor $2395 \mathrm{CD4}^{+}$and $\mathrm{CD8}^{+} \mathrm{T}^{-}$Cell Expansion in an Antigen Specific Manner}

To determine if iPSC-moDC and MDM are able to elicit an antigen specific $\mathrm{CD}^{+}$and $\mathrm{CD} 8^{+} \mathrm{T}$ cell response, iPSC-moDC or MDM from donor 2395 were activated with LPS/IFN $\gamma$, loaded with CEFX Ultra SuperStim Pool MHC-I and MHC-II subsets, and co-cultured with CFSE (ThermoFisher) stained total T cells from donor 2395. When 2395 total $\mathrm{T}$ cells were cultured with iPSC-MDM alone (Figure 4D; closed black circles), or LPS/ IFN $\gamma$-activated iPSC-MDM (Figure 4D; open black circles) there was little T cell expansion observed. However, when 2395 total T cells were cultured with CEFX peptide-loaded MDM (Figure 4D; closed red squares), or LPS/IFN $\gamma$-treated, CEFX peptide-loaded iPSC-MDM (Figure 4D; open red squares), there was significantly more expansion than when they were cultured with iPSC-MDM without peptide loading. iPSC-moDC also induced $\mathrm{T}$ cell expansion in an antigen specific manner. When total $\mathrm{T}$ cells were cultured with peptide-loaded iPSC-moDC (Figure 4E; closed red diamonds), expansion was increased compared to $\mathrm{T}$ cells cultured with iPSC-moDC alone (Figure 4E; closed black triangles). However, when iPSCmoDC were activated with LPS/IFN $\gamma$ first, there was no significant difference in $\mathrm{T}$ cell expansion when iPSC-moDC were peptide loaded (Figure 4E; open red diamond) compared to iPSC-moDC without peptide loading (Figure $4 \mathbf{E}$; open black triangles).

\section{Donor 2395 CD8 $^{+}$T Cell Avatars Bind to Donor $2395 \mathrm{EC}$ in an Antigen Specific Manner}

After $\mathrm{T}$ cells are activated, they must traffic to the islets of Langerhans. To exit the islet capillaries and enter the islets, $\mathrm{T}$ cells must migrate across the endothelial cell (EC) layer lining the insides of the capillaries in a process called extravasation [(47) and Figure 1C]. In this process, $\mathrm{T}$ cells first migrate to the site of inflammation via chemotaxis, they then must tether and roll across activated ECs before adhering, and finally transmigrating across the epithelium (47). To model the interactions of $\mathrm{CD}^{+} \mathrm{T}$ cells with vascular endothelium, we assessed $\mathrm{CD} 8^{+} \mathrm{T}$ cell avatars adhesion to an antigen-loaded iPSC-EC monolayer using cells from the same donor. As described recently (37), 2395 iPSC differentiate into iPSC-EC with morphology (Supplementary Figure 1A), cell surface marker profile (Supplementary Figure 1B), and functional capabilities similar to human aortic endothelial cells (HAEC). In this study 2395 iPSC efficiently differentiated into iPSC-EC with high a percentage of the cells being double positive for both CD31 and CD144 (84\% $\pm 8, n=4)$. Here, an in vitro hydrodynamic flow chamber adhesion assay was performed with monolayers of iPSC-EC from donor 2395 and either IGRP avatars or MART-1 avatars from 2395. When the 2395 iPSC-EC monolayer was not presenting antigenic peptide, the 2395 IGRP avatars failed to adhere strongly and were displaced at higher laminar flow rates (Figure 5A; black). Similarly, when the 2395 iPSC-EC monolayer was pulsed with the peptide antigen recognized by the MART-1 TCR, Melan- $\mathrm{A}_{26-35}$ (EAAGIGILTV), 2395 IGRP avatars detached at higher flow rates (Figure 5A; red). In contrast, 2395 IGRP avatars formed strong adhesions with the IGRP $265-273$ peptide-pulsed iPSC-EC monolayer and remained attached at higher flow rates (Figure 5A; gray). We confirmed the system's utility with a 
A

Monocytes
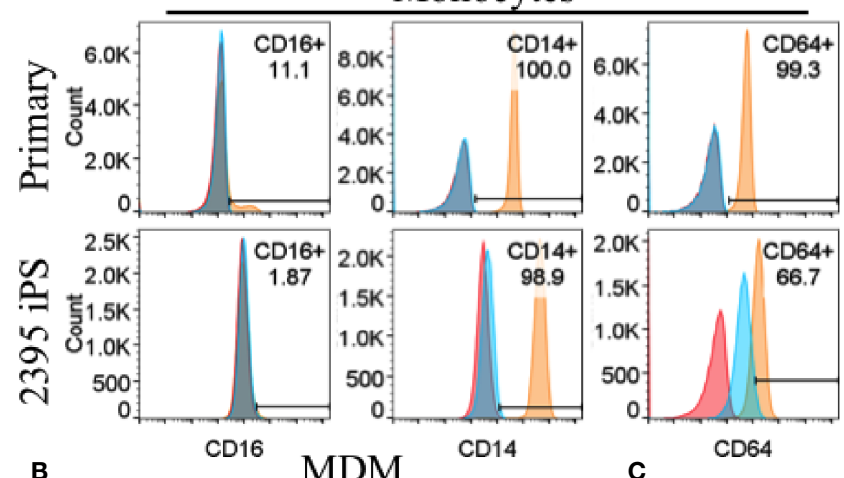

Unstained
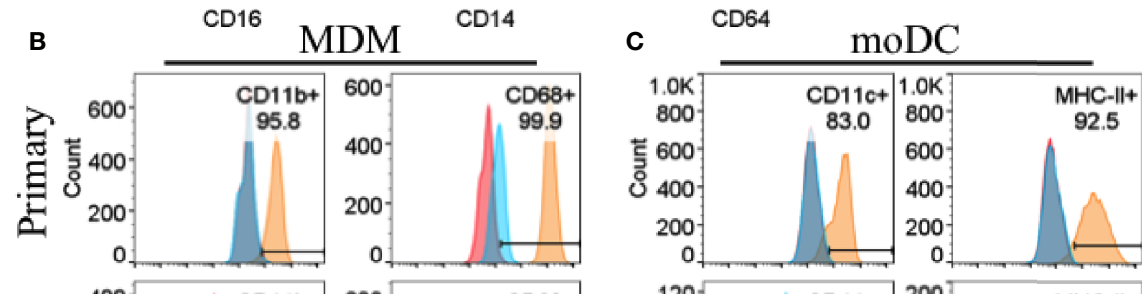

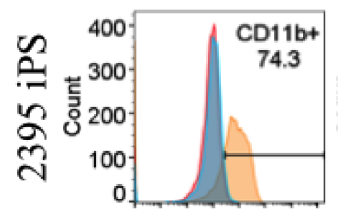

CD11b

D
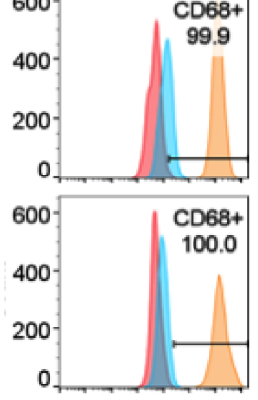

CD68
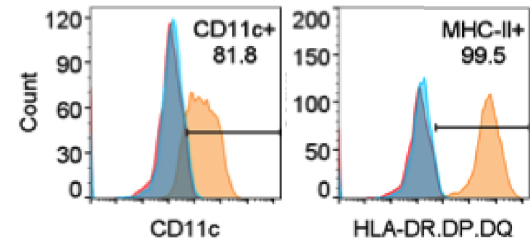

E

$T$ cells with moDC

HLA-DR.DP.DQ

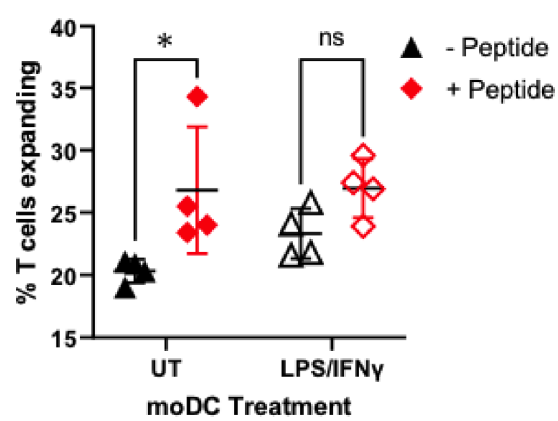

FIGURE 4 | Donor 2395 iPSC differentiate efficiently to monocytes, monocyte-derived macrophages (MDM) and monocyte-derived dendritic cells (moDC) and induce antigen specific $\mathrm{CD}_{4}^{+}$and $\mathrm{CD} 8^{+} \mathrm{T}$ cell expansion. (A) Donor 2395 iPSC-derived monocytes are CD16 $\mathrm{CD}^{-} 4^{+}$, and $\mathrm{CD}_{4} 4^{+}$similar to primary classical monocytes isolated from blood. (B) Donor 2395 iPSC-derived MDM express CD11b and CD68 similar to primary MDM. (C) Donor 2395 iPSC-derived moDC express CD11C and MHC-II similar to primary moDC. (D) iPSC-MDM expand Total T cells in an antigen specific manner. When antigen (CEFX peptide pools) is present, there is a significantly increased expansion of T cells compared to when Total T cells are cultured with APC alone (2-way ANOVA ${ }^{* *} \mathrm{p}=0.0011$ with 3 experimental repeats). (E) iPSC-moDC expand Total T cells in an antigen specific manner. When antigen is present, there is a significantly increased expansion of $\mathrm{T}$ cells compared to when Total $\mathrm{T}$ cells are cultured with APC alone (2-way ANOVA * $p=0.0104$ with 4 experimental repeats). Significance shown on the graphs were from post-hoc analysis utilizing the Šidák method to correct for multiple comparisons. ${ }^{*}$ indicates that $\mathrm{p}<0.05,{ }^{* *}$ indicates that $\mathrm{p}<0.01$, and ns indicates not significant.

second TCR and antigen, 2395 MART-1 avatars and the peptide it recognizes, Melan- $\mathrm{A}_{26-35}$. Using the laminar flow system without peptide the MART-1 avatars failed to form firm adhesions with the iPSC-EC monolayer (Figure 5B; black). Addition of IGRP $_{265-273}$ did not facilitate adhesion as this peptide is not recognized by the MART-1 avatars (Figure 5A; gray). In contrast, 2395 MART-1 avatars made firm adhesions with the Melan- $\mathrm{A}_{26-35}$ peptide-pulsed iPSC-EC monolayer as observed by binding at higher flow rates (Figure 5A; red). As vascular adhesion interactions are critical for $\mathrm{T}$ cell trafficking into pancreatic islets for targeted destruction of $\beta$-cells in T1D $(15,48-50)$, this proof-of-concept study demonstrates the utility of an antigen-dependent system for assessing interactions of $\mathrm{T}$ cells with endothelial cells. The ability to model these interactions with human cells allows for intensive interrogation of genetics regulating vascular inflammation or therapeutics meant to disrupt lymphocyte adhesion with vascular endothelial cells (Figure 1C). 
A

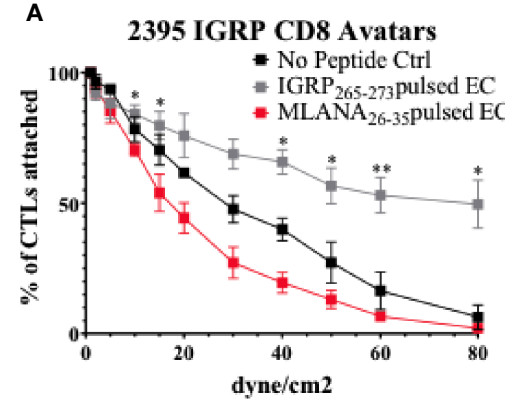

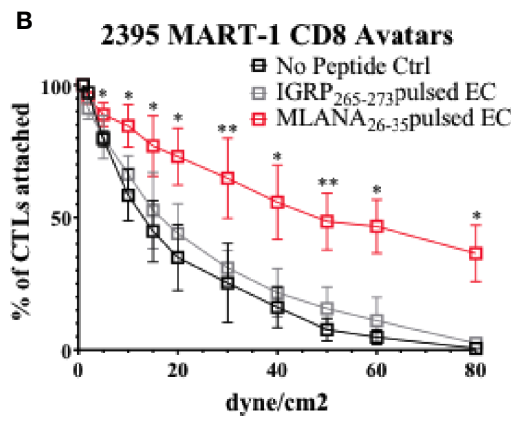

FIGURE 5 | Donor 2395 CD8 $^{+}$T cell avatars exhibit antigen specific binding to donor 2395 iPS-EC. (A) When donor 2395 IGRP CD8 ${ }^{+}$T cell avatars are flowed across a donor 2395 iPSC-derived endothelial cell (iPS-EC) monolayer loaded with IGRP peptide, the IGRP CD8 ${ }^{+} \mathrm{T}_{\text {cell }}$ avatars adhere more than MART- 1 CD8 ${ }^{+}$ T cell avatars or when the iPS-EC is not loaded with peptide. (B) When donor 2395 MART-1 CD8 ${ }^{+}$T cell avatars are flowed across a donor 2395 iPSC-derived endothelial cell (iPS-EC) monolayer loaded with Melan-A $26-35$, the MART-1 CD8 ${ }^{+} \mathrm{T}$ cell avatars adhere more than IGRP CD8 ${ }^{+} \mathrm{T}$ cell avatars or when the iPS-EC is not loaded with peptide. All in vitro hydrodynamic flow assay experiments were repeated 3 times. Significance shown on the graphs were from post-hoc analysis utilizing the Fisher's LSD test. * indicates that $p<0.05$ and ${ }^{* *}$ indicates that $p<0.01$.

\section{Donor 2395 CD8 $^{+}$T Cell Avatars Efficiently Target Donor 2395 sBC in an Antigen Specific Manner}

To determine if sBC are able to be targeted by $\mathrm{CD}^{+} \mathrm{T}$ cells in an antigen specific manner, a cell mediated lymphocytocixity (CML) assay was run with dispersed clusters of sBC differentiated from 1023,2395 , or $1-018$ as targets. The HLA- $A^{\star} 0201^{+}$human $\beta$ L5 cell line and dispersed HLA- $\mathrm{A}^{\star} 0201^{+}$human islet cells were used as positive controls (Figure 6). These groups were co-cultured with donor $2395 \mathrm{~T}$ cell avatars expressing a $\mathrm{T}$ cell receptor that recognizes a peptide from IGRP in the context of HLA-A ${ }^{\star} 0201$ $(39,40)$. The 2395 IGRP-avatars were able to target and kill the HLA-A ${ }^{\star} 0201$ expressing $\beta$ L5 and primary human islets (Figure 6A). In addition, cells differentiated from 1-023 and 2395 were lysed by the avatars (Figure 6A) as they carry HLA$\mathrm{A}^{\star} 0201$ (Table 1). Cells from 1-018 were not killed by the avatars (Figure 6A) as these cells do not have the correct HLA restriction (Table 1). We also assessed the ability of 2395 MART-1 T cell avatars that recognize a non- $\beta$-cell peptide derived from Melan$\mathrm{A}_{26-35}(20,51)$ to target and destroy cells that were pulsed with this Melan-A peptide or left untreated. MART-1-avatars were able to target and lyse both $\beta \mathrm{L} 5$ and 2395 sBC when the peptide was present in a fashion that was regulated by the number of MART-1 avatars added (Figure 6B). However, when the $\beta \mathrm{L} 5$ or $2395 \mathrm{sBC}$ were not pulsed with Melan- $A_{26-35}$, neither population of cells was lysed. These results indicate that $\mathrm{sBC}$ can be utilized to study the interactions of $\beta$-cells with antigen specific $\mathrm{T}$ cells. In addition, as $2395 \mathrm{~T}$ cell avatars kill $2395 \mathrm{sBC}$ in an antigen-specific fashion (Figure 6B) this isogenic system is a viable method to study interactions of autoreactive T cells with $\beta$-cells.

\section{DISCUSSION AND CONCLUSION}

While T1D develops in genetically at-risk individuals, our current understanding of the pathogenesis of T1D in humans continues to evolve due to the complexities of genetic risk in combination with environmental factors (52). Recent GWAS efforts have dramatically expanded the number of loci that are associated with both increased or decreased risk for T1D (1-12). The mechanisms linking the majority of these polymorphisms, alleles, and allotypes to the development of T1D are not clear. Disease heterogeneity in T1D may result from the dissimilar combinations of genes inherited by at risk individuals that instigate variations in onset age and disease endotypes. Indeed, specific combinations of risk HLA haplotypes have been linked to earlier age of onset as well as changes in the immune cell components of the insulitic lesion (53). Due to the impact of total combined genetic risk, it is necessary to sufficiently power mechanistic studies with large sample sizes to determine the responsibility of a single polymorphism to T1D and the cell types influenced by the greater than 100 polymorphisms that are linked to T1D (1-12). With the development of isogenic systems, such as that described here, methodologies have advanced that allow for interrogation of the effect of a single polymorphism in the absence of other genetic differences. Models derived from primary cells can lack reproducibility because certain cell types (i.e. $\beta$-cells) are not renewable; utilizing iPSC circumvents this issue. Herein we have shown that key cell types involved in the pathogenesis of T1D (Figure 1) can be derived from a single donor and used to construct an isogenic system to interrogate relevant cell-cell interactions. This renewable system provides a powerful platform to interrogate how specific genetic polymorphisms influence both cell function and cell-cell interactions in isolation of other genetic differences.

Thus far, we have observed that 2395 iPSC are pluripotentusing via trilineage differentiation, demonstrating that 2395 iPSC are capable of forming all 3 germ layers in vitro (Figure 2C). Further, 2395 iPSC express the pluripotency markers, OCT4 and NANOG (Figure 2B), and differentiate into functional cells from the endoderm (Figures 3, 5, 6) and mesoderm (Figure 4). However, prior to use of 2395 cells an in vivo model it will be essential to determine teratoma formation and tumorigenic potential. In this 
A

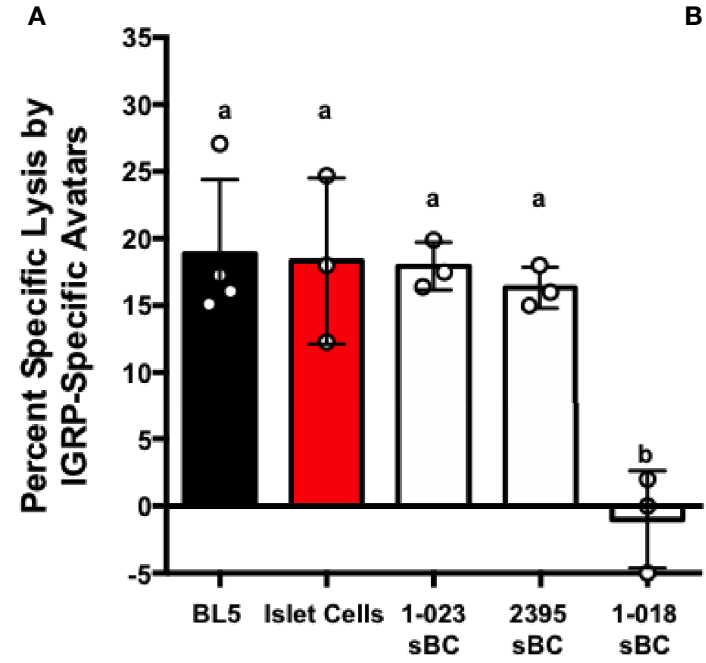

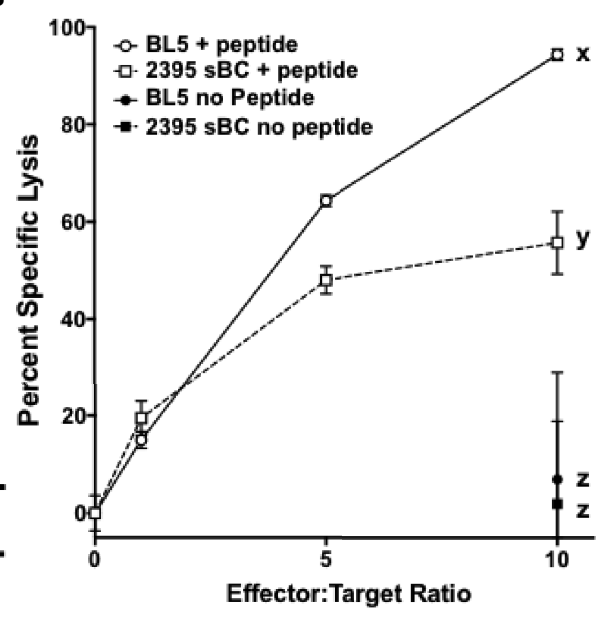

FIGURE 6 | sBC are efficiently targeted by donor 2395 CD8 $^{+}$T cell avatars in an antigen specific and HLA restricted manner. (A) Donor 2395 IGPR T cell avatars were co-cultured with $\beta L 5$ cells, primary islet cells from a HLA-A*0201 positive donor, 1-023 sBC, or 2395 sBC the cells were effectively lysed at an effector to target (E:T) ratio of 10:1. As 1-018 sBC do not harbor HLA-A*0201 these cells were not lysed by these $T$ cell avatars as they require the IGRP peptide to be presented by HLA-A*0201. (B) Donor 2395 MART-1-avatars were co-cultured with either $\beta L 5$ cells or donor 2395 sBC at increasing E:T ratios (0:1, 1:1, 5:1, and 10:1). When pulsed with Melan- $A_{26-35}$, lysis of both $\beta L 5$ and 2395 sBC increased with escalating E:T ratios. In the absence of Melan- $A_{26-35}$, no lysis was measured. *Letters denote significance: groups/lines with different letters were statistically significant $(P<0.05)$, whereas those with the same letter were not statistically different. These data are from at least 3 independent studies performed in triplicate.

isogenic system derived from donor 2395, we have shown that both macrophages and DC can expand total T cells (Figure 4), that $\mathrm{CD}^{+} \mathrm{T}$ cell avatars bind to $\mathrm{EC}$ in an antigen specific manner (Figure 5), and that $\mathrm{CD}^{+} \mathrm{T}$ cell avatars can target and lyse sBC that is dependent on the trimolecular complex (Figure 6). The current system affords power for interrogating these simple cellcell interactions as well as more complex cell-cell interactions such as macrophage, $\mathrm{T}$ cell, and $\beta$-cell interactions. While the system has great utility, it does however have limitations.

One of the current requirements of the current system is the need to recall specific donors to obtain $\mathrm{T}$ cells. This necessitates proper IRB approval and flexibility of research participants and investigators to schedule blood draws. Currently there are protocols for obtaining $\mathrm{T}$ cells from iPSC however these produce predominantly $\mathrm{CD}^{+} \mathrm{T}$ cells and very few $\mathrm{CD}^{+} \mathrm{T}$ cells $(54,55)$. The addition of iPSC-derived naïve autoreactive $\mathrm{CD}^{+} \mathrm{T}$ cells to this system can be implemented to provide yet another way for interrogation of cell-cell interactions and eliminate the need to recall donors to obtain $\mathrm{CD}^{+} \mathrm{T}$ cells. iPSC can be transduced with lentiviral vectors $(56,57)$, therefore a system to develop antigen specific iPSC-T cells could be employed wherein the iPSC are engineered to express a specific TCR to recognize self or nominal antigens.

Another shortcoming of this system and iPSC in general is that not all iPSC lines efficiently differentiate into all necessary cell types. For example, 1-018 sBC were not as functional as sBC from lines 1-023 or 2395 (Figure 3E). In addition, while 1-023 differentiated well into $\mathrm{sBC}$, this iPSC line did not produce monocytes. Lack of monocytes prevented downstream differentiation to macrophages and dendritic cells. Other groups have observed that lineage differentiation capacity is dependent on the iPSC line necessitating protocol optimization for lines that fail to differentiate effectively (58). As such, methodological modifications specific for 1-023 may resolve the observed dearth of monocytes from this line. However, the necessity of individualized differentiation protocols could impact the throughput of any system. Another important consideration and potential difficulty results from the complexity of T1D genetics. This requires careful consideration of the cells utilized for differentiation and study. Due to the strong genetic influence of the HLA super locus on T1D and the need for specific HLA alleles to be present for antigen specific studies, genotyping and selecting iPSC with HLA alleles (Table 1) that match TCRs to be utilized is essential. Here we eliminated 1-018 from the system as this line did not have the necessary HLA$\mathrm{A}^{\star} 0201$ allele to interact with the $\mathrm{T}$ cell avatars (Table 1). Indeed, 1-018 sBC were not targeted and lysed by the IGRP-Avatars (Figure 6A). The HLA Class I and Class II loci are the most polymorphic coding genes in the human genome (59), therefore matching HLA for the current study was prioritized. However, advances in gene editing technology may, in future studies, allow for extensive modification of HLA loci and obviate the requirement for excluding cells based on HLA allele types. Regardless of the more difficult requirements of the current system, there are many developing technologies that will improve future iterations.

One of the currently developing technologies is gene editing in iPSC. Gene editing can increase the flexibility of this system. There are numerous protocols for editing SNPs or knocking out genes in iPSC. While knockout is straightforward and there are 
high-efficiency protocols available for iPSC, easy to implement and high-efficiency protocols for scarless editing of single bases, such as SNPs, are still being developed (60-66). Once these high-efficiency protocols are developed, editing SNPs in iPSC will allow us to interrogate how credible risk or resistance SNPs influence these cell-cell interactions. The ability to edit iPSC donor lines to harbor both the T1D-risk and T1D-resistance alleles at a single locus will potentially suppress variation by allowing edited donor lines to be compared to each other. These methods would have exceptional value to study the genetic influences in cells, organoids, or organs that are difficult to access or genetically modify in a homogenous fashion. This would greatly facilitate the study of rare genetic variants (e.g. rs34536443 in TYK2, rs2476601 in PTPN22, rs35744605 in IFIH1, etc.) as editing iPSC lines to the rare minor alleles at T1D risk loci would allow for generation of numerous lines from different donors that could be studied in a pairwise fashion versus identifying and specifically recruiting donors with minor allele frequency (MAF) <0.05. For example, the frequency of individuals homozygous for the rare allele of $r s 34536443$ in TYK2 was recently reported to be 213 per 100,000 with MAF = $0.04(67,68)$. The ability to edit a credible risk or resistance SNP will facilitate determination of the impact of these rare variants and likely bolster efforts seeking to resolve the actual $\mathrm{SNP}(\mathrm{s})$ in linkage disequilibrium (LD) that influence disease risk (e.g. the $233 \mathrm{~kb} \mathrm{LD}$ block on chromosome $16 \mathrm{p} 13$ that contains CLEC16A) (69-71). In addition, other technologies in development, such as ESC and iPSC-derived thymii that can output functional naïve $\mathrm{T}$ cells, are novel tools for studying human disease etiology. As thymic epithelial cells (iPSC-TEC) $(72,73)$ have the potential to regulate $\mathrm{T}$ cell production from progenitors, use of these evolving technologies in combination (gene editing and iPSC-TEC) would allow for studies to dissect how T1D-linked loci, or those linked to other diseases, regulate $\mathrm{T}$ cell development. These and other currently advancing technologies will greatly enhance isogenic systems, improving their capacity to model human diseases.

Isogenic systems derived from iPSC will greatly augment our ability to interrogate key cellular interactions involved in genetic regulation of T1D pathogenesis. While the system built here is focused on T1D, it can be utilized to study cell-cell interactions and genetic regulation in the context of other human diseases. In summary, we have presented an isogenic model that can currently be used to interrogate many T1D-relevant cell-cell interactions. As more technologies for gene editing and differentiating iPSC continue to be developed these tools can be implemented to build a more relevant model capable of answering more complex questions.

\section{REFERENCES}

1. Barrett JC, Clayton DG, Concannon P, Akolkar B, Cooper JD, Erlich HA, et al. Genome-Wide Association Study and Meta-Analysis Find That Over 40 Loci Affect Risk of Type 1 Diabetes. Nat Genet (2009) 41:703-7.. doi: 10.1038/ ng.381

2. Bradfield JP, Qu H-Q, Wang K, Zhang H, Sleiman PM, Kim CE, et al. A Genome-Wide Meta-Analysis of Six Type 1 Diabetes Cohorts Identifies

\section{DATA AVAILABILITY STATEMENT}

The SNP typing data will be available to academic investigators upon request.

\section{AUTHOR CONTRIBUTIONS}

LHA, SES, CEM, and MAW conceived the idea, designed the research plan, and participated in all aspects of writing the manuscript. KS, LS, SO, BN, MH, JT, NF, PS, IR, RC-G, DP, HR, AS, NT, TB, JC, and DE performed experiments, analyzed data, interpreted results of experiments, and edited the manuscript. All authors contributed to the article and approved the submitted version.

\section{FUNDING}

This work was supported by research grants from the National Institutes of Health UC4 DK104194 (CM), R01 DK127497 (CM), UG3 DK122638 (TB, CM), P01 AI042288 (TB, CM), R01 DK103585 (DE), UC4 DK104207 (DE), R24 GM119977 (NT), F30 DK105788 (BN), T32 DK108736 (LA), UL1TR001427 (CTSI Pilot award to NF), R01 DK120444 (HR), R21 AI140044 (HR), a HIRN new investigator award (HR), a Culshaw Junior Investigator Award in Diabetes (HR), the Children's Diabetes Foundation (HR), the Sebastian Family Endowment for Diabetes Research (CM), the American Heart Association (16GRNT3098002 to NT), the JDRF 2-SRA-2019-781-S-B (HR), and the Leona and Harry Helmsley Charitable Trust (DE).

\section{ACKNOWLEDGMENTS}

The University of Florida Center for Immunology and Transplantation, The University of Florida Center for Cellular Reprogramming, The University of Florida Diabetes Institute, The University of Florida Clinical and Translational Science Institute, and the NIH funded Integrated Islet Distribution Program were all essential to the completion of these studies. This intra-institutional collaboration was facilitated by the Human Islet Research Network (https://hirnetwork.org/).

\section{SUPPLEMENTARY MATERIAL}

The Supplementary Material for this article can be found online at: https://www.frontiersin.org/articles/10.3389/fendo.2021.737276/ full\#supplementary-material

Multiple Associated Loci. PloS Genet (2011) 7:e1002293. doi: 10.1371/ journal.pgen.1002293

3. Chiou J, Geusz RJ, Okino M-L, Yun Han J, Miller M, Huang S, et al. Large-Scale Genetic Association and Single Cell Accessible Chromatin Mapping Defines Cell Type-Specific Mechanisms of Type 1 Diabetes Risk 2. (2021) 3:426472. doi: 10.1101/2021.01.13.426472

4. Cooper JD, Smyth DJ, Smiles AM, Plagnol V, Walker NM, Allen JE, et al. Meta-Analysis of Genome-Wide Association Study Data Identifies 
Additional Type 1 Diabetes Risk Loci. Nat Genet (2008) 40:1399-401. doi: 10.1038/ng.249

5. Grant SFA, Qu H-Q, Bradfield JP, Marchand L, Kim CE, Glessner JT, et al. Follow-Up Analysis of Genome-Wide Association Data Identifies Novel Loci for Type 1 Diabetes. Diabetes (2009) 58:290-5. doi: 10.2337/db08-1022

6. Hakonarson H, Grant SFA, Bradfield JP, Marchand L, Kim CE, Glessner JT, et al. A Genome-Wide Association Study Identifies KIAA0350 as a Type 1 Diabetes Gene. Nature (2007) 448:591-4. doi: 10.1038/nature06010

7. Hakonarson H, Qu H-Q, Bradfield JP, Marchand L, Kim CE, Glessner JT, et al. A Novel Susceptibility Locus for Type 1 Diabetes on Chr12q13 Identified by a Genome-Wide Association Study. Diabetes (2008) 57:1143-6. doi: $10.2337 / \mathrm{db} 07-1305$

8. Huang J, Ellinghaus D, Franke A, Howie B, Li Y. 1000 Genomes-Based Imputation Identifies Novel and Refined Associations for the Wellcome Trust Case Control Consortium Phase 1 Data. Eur J Hum Genet (2012) 20:801-5. doi: 10.1038/ejhg.2012.3

9. Noble JA, Valdes AM. Genetics of the HLA Region in the Prediction of Type 1 Diabetes. Curr Diab Rep (2011) 11:533-42. doi: 10.1007/s11892-011-0223-x

10. Onengut-Gumuscu S, Chen W-M, Burren O, Cooper NJ, Quinlan AR, Mychaleckyj JC, et al. Fine Mapping of Type 1 Diabetes Susceptibility Loci and Evidence for Colocalization of Causal Variants With Lymphoid Gene Enhancers. Nat Genet (2015) 47:381-6. doi: 10.1038/ng.3245

11. Robertson CC, Inshaw JRJ, Onengut-Gumuscu S, Wei-Min, Chen W-M, Santa Cruz DF, Yang H, et al. Fine-Mapping, Trans-Ancestral and Genomic Analyses Identify Causal Variants, Cells, Genes and Drug Targets for Type 1 Diabetes. Nat Genet (2021) 53:962-71. doi: 10.1038/s41588-021-00880-5

12. Todd JA, Walker NM, Cooper JD, Smyth DJ, Downes K, Plagnol V, et al. Robust Associations of Four New Chromosome Regions From Genome-Wide Analyses of Type 1 Diabetes. Nat Genet (2007) 39:857-64. doi: $10.1038 / \mathrm{ng} 2068$

13. Drexhage HA, Dik WA, Leenen PJM, Versnel MA. The Immune Pathogenesis of Type 1 Diabetes: Not Only Thinking Outside the Cell But Also Outside the Islet and Out of the Box. Diabetes (2016) 65:2130-3. doi: 10.2337/dbi16-0030

14. Mathews CE, Graser RT, Savinov A, Serreze DV, Leiter EH. Unusual Resistance of ALR/Lt Mouse Beta Cells to Autoimmune Destruction: Role for Beta Cell-Expressed Resistance Determinants. Proc Natl Acad Sci USA (2001) 98:235-40. doi: 10.1073/pnas.98.1.235

15. Whitener RL, Gallo Knight L, Li J, Knapp S, Zhang S, Annamalai M, et al. The Type 1 Diabetes-Resistance Locus Idd22 Controls Trafficking of Autoreactive CTLs Into the Pancreatic Islets of NOD Mice. J Immunol (2017) 199:39914000. doi: 10.4049/jimmunol.1602037

16. Driver JP, Chen Y-GG, Mathews CE. Comparative Genetics: Synergizing Human and NOD Mouse Studies for Identifying Genetic Causation of Type 1 Diabetes. Rev Diabet Stud (2012) 9:169-87. doi: 10.1900/RDS.2012.9.169

17. Bonder MJ, Smail C, Gloudemans MJ, Frésard L, Jakubosky D, D’Antonio M, et al. Identification of Rare and Common Regulatory Variants in Pluripotent Cells Using Population-Scale Transcriptomics. Nat Genet (2021) 53:313-21. doi: 10.1038/s41588-021-00800-7

18. Johnson LA, Morgan RA, Dudley ME, Cassard L, Yang JC, Hughes MS, et al. Gene Therapy With Human and Mouse T-Cell Receptors Mediates Cancer Regression and Targets Normal Tissues Expressing Cognate Antigen. Blood (2009) 114:535-46. doi: 10.1182/blood-2009-03-211714

19. Morgan RA, Dudley ME, Wunderlich JR, Hughes MS, Yang JC, Sherry RM, et al. Cancer Regression in Patients After Transfer of Genetically Engineered Lymphocytes. Science (2006) 314:126-9. doi: 10.1126/science.1129003

20. Newby BN, Brusko TM, Zou B, Atkinson MA, Clare-Salzler M, Mathews CE. Type 1 Interferons Potentiate Human CD8+ T-Cell Cytotoxicity Through a STAT4- and Granzyme B-Dependent Pathway. Diabetes (2017) 66:3061-71. doi: $10.2337 / \mathrm{db} 17-0106$

21. Johannesson B, Sagi I, Gore A, Paull D, Yamada M, Golan-Lev T, et al. Comparable Frequencies of Coding Mutations and Loss of Imprinting in Human Pluripotent Cells Derived by Nuclear Transfer and Defined Factors. Cell Stem Cell (2014) 15:634-42. doi: 10.1016/j.stem.2014.10.002

22. Sui L, Danzl N, Campbell SR, Viola R, Williams D, Xing Y, et al. $\beta$-Cell Replacement in Mice Using Human Type 1 Diabetes Nuclear Transfer Embryonic Stem Cells. Diabetes (2018) 67:26-35. doi: 10.2337/db17-0120

23. Yamada M, Johannesson B, Sagi I, Burnett LC, Kort DH, Prosser RW, et al. Human Oocytes Reprogram Adult Somatic Nuclei of a Type 1 Diabetic to
Diploid Pluripotent Stem Cells. Nature (2014) 510:533-6. doi: 10.1038/ nature 13287

24. Taylor JP, Cash MN, Santostefano KE, Nakanishi M, Terada N, Wallet MA. CRISPR/Cas9 Knockout of USP18 Enhances Type I IFN Responsiveness and Restricts HIV-1 Infection in Macrophages. J Leukoc Biol (2018) 103:1225-40. doi: 10.1002/JLB.3MIA0917-352R

25. Nishimura K, Sano M, Ohtaka M, Furuta B, Umemura Y, Nakajima Y, et al. Development of Defective and Persistent Sendai Virus Vector: A Unique Gene Delivery/Expression System Ideal for Cell Reprogramming. J Biol Chem (2011) 286:4760-71. doi: 10.1074/jbc.M110.183780

26. Nishimura K, Ohtaka M, Takada H, Kurisaki A, Tran NVK, Tran YTH, et al. Simple and Effective Generation of Transgene-Free Induced Pluripotent Stem Cells Using an Auto-Erasable Sendai Virus Vector Responding to microRNA302. Stem Cell Res (2017) 23:13-9. doi: 10.1016/j.scr.2017.06.011

27. Docherty FM, Riemondy KA, Castro-Gutierrez R, Dwulet JM, Shilleh AH, Hansen MS, et al. ENTPD3 Marks Mature Stem Cell Derived Beta Cells Formed by Self-Aggregation in Vitro. Diabetes (2021) db200873. doi: 10.2337/ db20-0873

28. Russ HA, Parent AV, Ringler JJ, Hennings TG, Nair GG, Shveygert M, et al. Controlled Induction of Human Pancreatic Progenitors Produces Functional Beta-Like Cells In Vitro. EMBO J (2015) 34:1759-72. doi: 10.15252/ embj.201591058

29. Faleo G, Russ HA, Wisel S, Parent AV, Nguyen V, Nair GG, et al. Mitigating Ischemic Injury of Stem Cell-Derived Insulin-Producing Cells After Transplant. Stem Cell Rep (2017) 9:807-19. doi: 10.1016/j.stemcr.2017.07.012

30. Cortes A, Brown MA. Promise and Pitfalls of the Immunochip. Arthritis Res Ther (2011) 13:101. doi: 10.1186/ar3204

31. Romanel A, Zhang T, Elemento O, Demichelis F. EthSEQ: Ethnicity Annotation From Whole Exome Sequencing Data. Bioinformatics (2017) 33:2402-4. doi: 10.1093/bioinformatics/btx165

32. Manichaikul A, Mychaleckyj JC, Rich SS, Daly K, Sale M, Chen W-M. Robust Relationship Inference in Genome-Wide Association Studies. Bioinformatics (2010) 26:2867-73. doi: 10.1093/bioinformatics/btq559

33. Das S, Forer L, Schönherr S, Sidore C, Locke AE, Kwong A, et al. NextGeneration Genotype Imputation Service and Methods. Nat Genet (2016) 48:1284-7. doi: $10.1038 /$ ng. 3656

34. Jie Huang MMP, Yuan Lin MP. Genotyping Technologies and Applications in the Era of Precision Medicine. North Am J Med Sci (2017) 10:176-80.

35. Armitage LH, Khosravi-Maharlooei M, Meacham A, Butfiloski EJ, Viola R, Egli D, et al. High-Yield Monocyte, Macrophage, and Dendritic Cell Differentiation From Induced Pluripotent Stem Cells Running Title: High-Yield Monocyte Differentiation From hiPSC. BioRxiv (2021). 2021.04.29.441947.

36. Vopenkova K, Mollova K, Buresova I, Michalek J. Complex Evaluation of Human Monocyte-Derived Dendritic Cells for Cancer Immunotherapy. J Cell Mol Med (2012) 16:2827-37. doi: 10.1111/j.1582-4934.2012.01614.x

37. Fredette NC, Malik E, Mukhtar ML, Prossnitz ER, Terada N. A Hypertension Patient-Derived iPSC Model Demonstrates a Role for G Protein-Coupled Estrogen Receptor in Hypertension Risk and Development. Am J Physiol Cell Physiol (2020) 319:C825-38. doi: 10.1152/ajpcell.00350.2019

38. Tan JY, Sriram G, Rufaihah AJ, Neoh KG, Cao T. Efficient Derivation of Lateral Plate and Paraxial Mesoderm Subtypes From Human Embryonic Stem Cells Through GSKi-Mediated Differentiation. Stem Cells Dev (2013) 22:1893-906. doi: 10.1089/scd.2012.0590

39. Brusko TM, Koya RC, Zhu S, Lee MR, Putnam AL, McClymont SA, et al. Human Antigen-Specific Regulatory T Cells Generated by T Cell Receptor Gene Transfer. PloS One (2010) 5:e11726. doi: 10.1371/journal.pone.0011726

40. Driver JP, Racine JJ, Ye C, Lamont DJ, Newby BN, Leeth CM, et al. Interferon$\gamma$ Limits Diabetogenic CD8+ T-Cell Effector Responses in Type 1 Diabetes. Diabetes (2017) 66:710-21. doi: 10.2337/db16-0846

41. Sharp CD, Huang M, Glawe J, Patrick DR, Pardue S, Barlow SC, et al. Stromal Cell-Derived Factor-1/CXCL12 Stimulates Chemorepulsion of NOD/LtJ TCell Adhesion to Islet Microvascular Endothelium. Diabetes (2008) 57:10212. doi: $10.2337 / \mathrm{db} 07-0494$

42. Schneider CA, Rasband WS, Eliceiri KW. Image to ImageJ: 25 Years of Image Analysis. Nat Methods (2012) 9:671-5. doi: 10.1038/nmeth.2089

43. Chen J, Grieshaber S, Mathews CE. Methods to Assess Beta Cell Death Mediated by Cytotoxic T Lymphocytes. J Vis Exp (2011) (52):e2724. doi: $10.3791 / 2724$ 
44. Sui L, Leibel RL, Egli D. Pancreatic Beta Cell Differentiation From Human Pluripotent Stem Cells. Curr Protoc Hum Genet (2018) 99:e68. doi: 10.1002/ cphg. 68

45. Shapiro MR, Yeh W-I, Longfield JR, Gallagher J, Infante CM, Wellford S, et al. CD226 Deletion Reduces Type 1 Diabetes in the NOD Mouse by Impairing Thymocyte Development and Peripheral T Cell Activation. Front Immunol (2020) 11:2180. doi: 10.3389/fimmu.2020.02180

46. Sharpe AH. Mechanisms of Costimulation. Immunol Rev (2009) 229:5-11. doi: 10.1111/j.1600-065X.2009.00784.x

47. Muller WA. Getting Leukocytes to the Site of Inflammation. Vet Pathol (2013) 50:7-22. doi: 10.1177/0300985812469883

48. Martin S, van den Engel NK, Vinke A, Heidenthal E, Schulte B, Kolb H. Dominant Role of Intercellular Adhesion Molecule-1 in the Pathogenesis of Autoimmune Diabetes in Non-Obese Diabetic Mice. J Autoimmun (2001) 17:109-17. doi: 10.1006/jaut.2001.0526

49. Phillips JM, Haskins K, Cooke A. MAdCAM-1 Is Needed for Diabetes Development Mediated by the T Cell Clone, BDC-2.5. Immunology (2005) 116:525-31. doi: 10.1111/j.1365-2567.2005.02254.x

50. Savinov AY, Strongin AY. Targeting the T-Cell Membrane Type-1 Matrix Metalloproteinase-CD44 Axis in a Transferred Type 1 Diabetes Model in NOD Mice. Exp Ther Med (2013) 5:438-42. doi: 10.3892/etm.2012.821

51. Blanchet JS, Valmori D, Dufau I, Ayyoub M, Nguyen C, Guillaume P, et al. A New Generation of Melan-A/MART-1 Peptides That Fulfill Both Increased Immunogenicity and High Resistance to Biodegradation: Implication for Molecular Anti-Melanoma Immunotherapy. J Immunol (2001) 167:585261. doi: 10.4049/jimmunol.167.10.5852

52. Wasserfall C, Nead K, Mathews C, Atkinson MA. The Threshold Hypothesis: Solving the Equation of Nurture vs Nature in Type 1 Diabetes. Diabetologia (2011) 54:2232-6. doi: 10.1007/s00125-011-2244-z

53. Inshaw JRJ, Cutler AJ, Crouch DJM, Wicker LS, Todd JA. Genetic Variants Predisposing Most Strongly to Type 1 Diabetes Diagnosed Under Age 7 Years Lie Near Candidate Genes That Function in the Immune System and in Pancreatic $\beta$-Cells. Diabetes Care (2020) 43:169-77. doi: 10.2337/dc19-0803

54. Kaneko S. In Vitro Generation of Antigen-Specific T Cells From Induced Pluripotent Stem Cells of Antigen-Specific T Cell Origin. Methods Mol Biol (2016) 1393:67-73. doi: 10.1007/978-1-4939-3338-9_6

55. Nishimura T, Kaneko S, Kawana-Tachikawa A, Tajima Y, Goto H, Zhu D, et al. Generation of Rejuvenated Antigen-Specific T Cells by Reprogramming to Pluripotency and Redifferentiation. Cell Stem Cell (2013) 12:114-26. doi: 10.1016/j.stem.2012.11.002

56. Naujok O, Diekmann U, Elsner M. Gene Transfer Into Pluripotent Stem Cells via Lentiviral Transduction. Methods Mol Biol (2016) 1341:67-85. doi: 10.1007/7651_2015_221

57. Zare M, Soleimani M, Mohammadian M, Akbarzadeh A, Havasi P, Zarghami N. Efficient Biotechnological Approach for Lentiviral Transduction of Induced Pluripotent Stem Cells. Artif Cells Nanomed Biotechnol (2016) 44:743-8. doi: 10.3109/21691401.2014.982804

58. Koyanagi-Aoi M, Ohnuki M, Takahashi K, Okita K, Noma H, Sawamura Y, et al. Differentiation-Defective Phenotypes Revealed by Large-Scale Analyses of Human Pluripotent Stem Cells. Proc Natl Acad Sci USA (2013) 110:2056974. doi: 10.1073/pnas.1319061110

59. Beck S, Geraghty D, Inoko H, Rowen L, Aguado B, Bahram S, et al. Complete Sequence and Gene Map of a Human Major Histocompatibility Complex. The MHC Sequencing Consortium. Nature (1999) 401:921-3. doi: $10.1038 / 44853$

60. Hou Z, Zhang Y, Propson NE, Howden SE, Chu L-F, Sontheimer EJ, et al. Efficient Genome Engineering in Human Pluripotent Stem Cells Using Cas9 From Neisseria Meningitidis. Proc Natl Acad Sci USA (2013) 110:15644-9. doi: $10.1073 /$ pnas. 1313587110

61. Ben Jehuda R, Shemer Y, Binah O. Genome Editing in Induced Pluripotent Stem Cells Using CRISPR/Cas9. Stem Cell Rev Rep (2018) 14:323-36. doi: 10.1007/s12015-018-9811-3
62. Li X-L, Li G-H, Fu J, Fu Y-W, Zhang L, Chen W, et al. Highly Efficient Genome Editing via CRISPR-Cas9 in Human Pluripotent Stem Cells Is Achieved by Transient BCL-XL Overexpression. Nucleic Acids Res (2018) 46:10195-215. doi: 10.1093/nar/gky804

63. Maguire JA, Cardenas-Diaz FL, Gadue P, French DL. Highly Efficient CRISPR-Cas9-Mediated Genome Editing in Human Pluripotent Stem Cells. Curr Protoc Stem Cell Biol (2019) 48:e64. doi: 10.1002/cpsc.64

64. Paquet D, Kwart D, Chen A, Sproul A, Jacob S, Teo S, et al. Efficient Introduction of Specific Homozygous and Heterozygous Mutations Using CRISPR/Cas9. Nature (2016) 533:125-9. doi: 10.1038/nature17664

65. Xu X, Gao D, Wang P, Chen J, Ruan J, Xu J, et al. Efficient HomologyDirected Gene Editing by CRISPR/Cas9 in Human Stem and Primary Cells Using Tube Electroporation. Sci Rep (2018) 8:11649. doi: 10.1038/ s41598-018-30227-w

66. Yumlu S, Bashir S, Stumm J, Kühn R. Efficient Gene Editing of Human Induced Pluripotent Stem Cells Using CRISPR/Cas9. Methods Mol Biol (2019) 1961:137-51. doi: 10.1007/978-1-4939-9170-9_10

67. Dendrou CA, Cortes A, Shipman L, Evans HG, Attfield KE, Jostins L, et al. Resolving TYK2 Locus Genotype-to-Phenotype Differences in Autoimmunity. Sci Transl Med (2016) 8:363ra149. doi: 10.1126/ scitranslmed.aag1974

68. Mero I-L, Lorentzen AR, Ban M, Smestad C, Celius EG, Aarseth JH, et al. A Rare Variant of the TYK2 Gene Is Confirmed to be Associated With Multiple Sclerosis. Eur J Hum Genet (2010) 18:502-4. doi: 10.1038/ ejhg.2009.195

69. Bakay M, Pandey R, Grant SFA, Hakonarson H. The Genetic Contribution to Type 1 Diabetes. Curr Diab Rep (2019) 19:116. doi: 10.1007/s11892-019-1235-1

70. Gingerich MA, Sidarala V, Soleimanpour SA. Clarifying the Function of Genes at the Chromosome 16p13 Locus in Type 1 Diabetes: CLEC16A and DEXI. Genes Immun (2020) 21:79-82. doi: 10.1038/s41435-019-0087-7

71. Zuvich RL, Bush WS, McCauley JL, Beecham AH, De Jager PLInternational Multiple Sclerosis Genetics Consortium, et al. Interrogating the Complex Role of Chromosome 16p13.13 in Multiple Sclerosis Susceptibility: Independent Genetic Signals in the CIITA-CLEC16A-SOCS1 Gene Complex. Hum Mol Genet (2011) 20:3517-24. doi: 10.1093/hmg/ddr250

72. Chhatta AR, Cordes M, Hanegraaf MAJ, Vloemans S, Cupedo T, Cornelissen JJ, et al. De Novo Generation of a Functional Human Thymus From Induced Pluripotent Stem Cells. J Allergy Clin Immunol (2019) 144:1416-1419.e7. doi: 10.1016/j.jaci.2019.05.042

73. Parent AV, Russ HA, Khan IS, LaFlam TN, Metzger TC, Anderson MS, et al. Generation of Functional Thymic Epithelium From Human Embryonic Stem Cells That Supports Host T Cell Development. Cell Stem Cell (2013) 13:21929. doi: 10.1016/j.stem.2013.04.004

Conflict of Interest: The authors declare that the research was conducted in the absence of any commercial or financial relationships that could be construed as a potential conflict of interest.

Publisher's Note: All claims expressed in this article are solely those of the authors and do not necessarily represent those of their affiliated organizations, or those of the publisher, the editors and the reviewers. Any product that may be evaluated in this article, or claim that may be made by its manufacturer, is not guaranteed or endorsed by the publisher.

Copyright (C) 2021 Armitage, Stimpson, Santostefano, Sui, Ogundare, Newby, CastroGutierrez, Huber, Taylor, Sharma, Radichev, Perry, Fredette, Savinov, Wallet, Terada, Brusko, Russ, Chen, Egli and Mathews. This is an open-access article distributed under the terms of the Creative Commons Attribution License (CC BY). The use, distribution or reproduction in other forums is permitted, provided the original author(s) and the copyright owner(s) are credited and that the original publication in this journal is cited, in accordance with accepted academic practice. No use, distribution or reproduction is permitted which does not comply with these terms. 